\title{
Cortisol as an Acute Stress Biomarker in Young Hematopoietic Cell Transplant Patients/Caregivers: Active Music Engagement Protocol
}

\author{
Kristen A. Russ, $\mathrm{PhD}^{1}$ Steven J. Holochwost, $\mathrm{PhD}^{2}$ Susan M. Perkins, $\mathrm{PhD}_{1}^{3,4}$ \\ Kristin Stegenga, PhD, RN, CPON, ${ }^{5}$ Seethal A. Jacob, MD, MS, FAAP, ${ }^{3,6}$ David Delgado, MD, \\ Amanda K. Henley, MM, MT-BC, ${ }^{8}$ Joan E. Haase, PhD, RN, FAAN, ${ }^{8}$ and Sheri L. Robb, PhD, MT-BC ${ }^{8}$
}

\begin{abstract} feasibility/acceptability of the biological sample collection schedule. lection schedules based on transplant type.

Setting/Location: Pediatric inpatient HSCT unit. 45-min AME sessions each week during hospitalization.

\footnotetext{
${ }^{1}$ Indiana University Melvin and Bren Simon Cancer Center, Indianapolis, IN, USA.

${ }^{2}$ WolfBrown, Boston, MA, USA.

${ }^{3}$ Indiana University School of Medicine, Indianapolis, IN, USA.

${ }^{4}$ Richard M. Fairbanks School of Public Health, Indianapolis, IN, USA.

${ }^{5}$ Children's Mercy Hospital, Kansas City, KS, USA.

${ }^{6}$ Riley Hospital for Children at IU Health, Indianapolis, IN, USA.

${ }^{7}$ Astellas Pharma Global Development, Northbrook, IL, USA.

${ }^{8}$ Indiana University School of Nursing, Indianapolis, IN, USA.
}

Objective: Primary aims of the proposed protocol are to determine the feasibility/acceptability of the active music engagement intervention protocol during hematopoietic stem cell transplantation (HSCT) and clinical

Design: The authors propose a single-case, alternating treatment design to compare levels of child and caregiver cortisol in blood and saliva collected on alternating days, when the dyad receives and does not receive AME sessions. Included are the scientific rationale for this design and detailed intervention and sample col-

Subjects: Eligible participants are dyads of children 3-8 years old, hospitalized for HSCT, and their caregiver. Children with malignant and nonmalignant conditions will be eligible, regardless of transplant type.

Intervention: AME intervention is delivered by a board-certified music therapist who tailors music-based play experiences to encourage active engagement in, and independent use of, music play to manage the interrelated emotional distress experienced by children and their caregivers during HSCT. Dyads will receive two

Outcome Measures: Eight collections of blood (child) and saliva (child/caregiver) will be performed for cortisol measurement. The authors will also collect self-report and caregiver proxy measures for dyad emotional distress, quality of life, and family function. At study conclusion, qualitative caregiver interviews will be conducted.

Results: Planned analyses will be descriptive and evaluate the feasibility of participant recruitment, cortisol collection, planned evaluations, and AME delivery. Analysis of qualitative interviews will be used to gain an understanding about the ease/burden of biological sample collection and any perceived benefit of AME.

Conclusions: Behavioral intervention studies examining biological mechanisms of action in pediatric transplant populations are rare. Findings will provide important information about the feasibility/acceptability

(C) Kristen A. Russ, et al. 2020; Published by Mary Ann Liebert, Inc. This Open Access article is distributed under the terms of the Creative Commons Attribution Noncommercial License (http://creativecommons.org/licenses/by-nc/4.0/) which permits any noncommercial use, distribution, and reproduction in any medium, provided the original author(s) and the source are cited. 
of collecting cortisol samples during a high-intensity treatment and advance understanding about the use of active music interventions to mitigate child/caregiver distress during the transplant period.

Keywords: biomarker, cortisol, stress, music therapy, pediatric, hematopoietic stem cell transplant

\section{Introduction}

$\mathbf{H}$ EMATOPOIETIC STEM CELL transplantation (HSCT) is the curative therapy of choice for many malignancies that require high-dose chemotherapy, and sometimes radiation therapy, and the only curative therapy option for some nonmalignant conditions such as hemoglobinopathies. ${ }^{1}$ Regardless of diagnosis, HSCT is an intense complex treatment with many risks. Young children undergoing HSCT and their caregivers are at particular risk for heightened emotional distress, which is associated with physical symptom distress and diminished quality of life and family function. ${ }^{2-9}$ In addition, this acute emotional distress is related to traumatic stress symptoms after treatment ends. ${ }^{8,10-15}$ Despite evidence that young child and caregiver distress is inter-related, few interventions have been developed to address this shared distress $^{3,8,9,13,16,17}$ and fewer specific to transplants. ${ }^{18}$

The active music engagement intervention uses music play experiences to diminish stressful qualities of the treatment environment, encouraging engagement and the use of positive coping strategies to reduce the emotional/traumatic distress experienced by young children (ages 3-8 years) and caregivers and improve quality of life. ${ }^{19-21}$ Early studies established AME as beneficial in managing child emotional distress ${ }^{19-21}$ and explored caregiver benefit. ${ }^{21}$ The aim of the current R01 mechanistic trial (NR015789) is to identify behavioral, sociological, and psychological variables that contribute to positive health outcomes observed in early AME studies. To date, the authors' studies have focused on short inpatient admissions for chemotherapy and identification of psychosocial mechanisms of action. In this study, the authors will explore the feasibility/acceptability of AME during the acute phase of HSCT, which is a high-intensity treatment requiring 3-6 weeks of hospitalization. In addition, to expand the understanding about how active music interventions work to mitigate transplant-related stress, the authors will also explore the feasibility/acceptability of collecting the stress biomarker, cortisol, from children and caregivers.

Evidence that increased hypothalamic-pituitary-adrenal (HPA) axis activity stimulates the release and production of inflammatory biomarkers, which in turn is associated with negative health outcomes for individuals undergoing treatment for chronic conditions and caregivers, supports investigation of biological pathways underlying the use of active music to mitigate transplant-related stress. ${ }^{22-24}$ Cortisol is a steroid hormone secreted by the HPA axis in response to acute and prolonged stress, and assaying various bodily fluids for cortisol is a widely used method of indexing HPA axis activity in children. ${ }^{25}$ To date, few intervention studies have looked at cortisol in pediatric patients with malignant and nonmalignant conditions, ${ }^{26-28}$ and of those, only one used music $^{28}$ and none involved children and caregivers. ${ }^{26-28}$ This is likely due to challenges associated with cortisol collection and interpretation during cancer and HSCT treatment and difficulties conducting fully powered, randomized intervention trials in low-incidence populations. ${ }^{29-31}$ To overcome these challenges, the authors propose a single-case design study, which allows for estimation of intervention effects in small samples drawn from low-incidence populations.

The authors' primary aims are to determine the feasibility/acceptability of the AME intervention protocol during HSCT and evaluate clinical feasibility/acceptability of the schedule for biological samples required when using a singlecase design. If the authors meet feasibility thresholds for blood and salivary cortisol (collection and sample quantity/quality), they will examine changes in parent and child cortisol levels relative to the AME intervention. The secondary aim is to examine the feasibility of completing self-report measures used in prior AME studies in the context of HSCT. This secondary aim will also establish whether it is feasible/acceptable to collect both biological and self-report data during a high-intensity treatment in subsequent trials. Areas of evaluation include activities/timelines related to recruitment, blood and salivary cortisol collection, planned evaluations, and intervention delivery. Specific research questions are as follows:

(1) What percentage of eligible child/caregiver dyads consent to study participation?

(2) What percentage of AME sessions do child/caregiver dyads complete?

(3) What percentage of planned measures [other than cortisol] do caregivers complete?

(4) What percentage of planned cortisol samples are collected and what percentage of these samples yield usable data?

(5) What are caregivers' perspectives about the relative ease/burden of biological sample collection, benefit (or nonbenefit) of AME for managing distress, and enhancing family and quality of life outcomes for self and child?

\section{Materials and Methods}

\section{Conceptual framework}

The conceptual framework (Fig. 1) is based on Robb's Contextual Support Model of Music Therapy ${ }^{19,32,33}$ and further informed by Kazak's Pediatric Medical Traumatic Stress Model, which provides a useful heuristic for understanding short- and long-term consequences of HSCT treatment for children and caregivers. ${ }^{4}$ In this framework, recurring events related to HSCT (i.e., hospitalization, symptom distress, and procedures) are viewed as potentially traumatic events. Caregiver appraisal of events as traumatic or not traumatic is influenced by pre-existing factors, which serve as antecedents. Research indicates that higher child and caregiver distress during HSCT is related to (1) demographics (younger child/caregiver age, female caregiver gender, and lower socioeconomic status/education), ${ }^{34,35}$ (2) higher caregiver/child distress with prior hospitalizations and greater traumatic stress symptoms, ${ }^{2,36,37}$ and (3) disease and treatment characteristics (diagnosis and transplant type). $5,12,14,15,38$ 


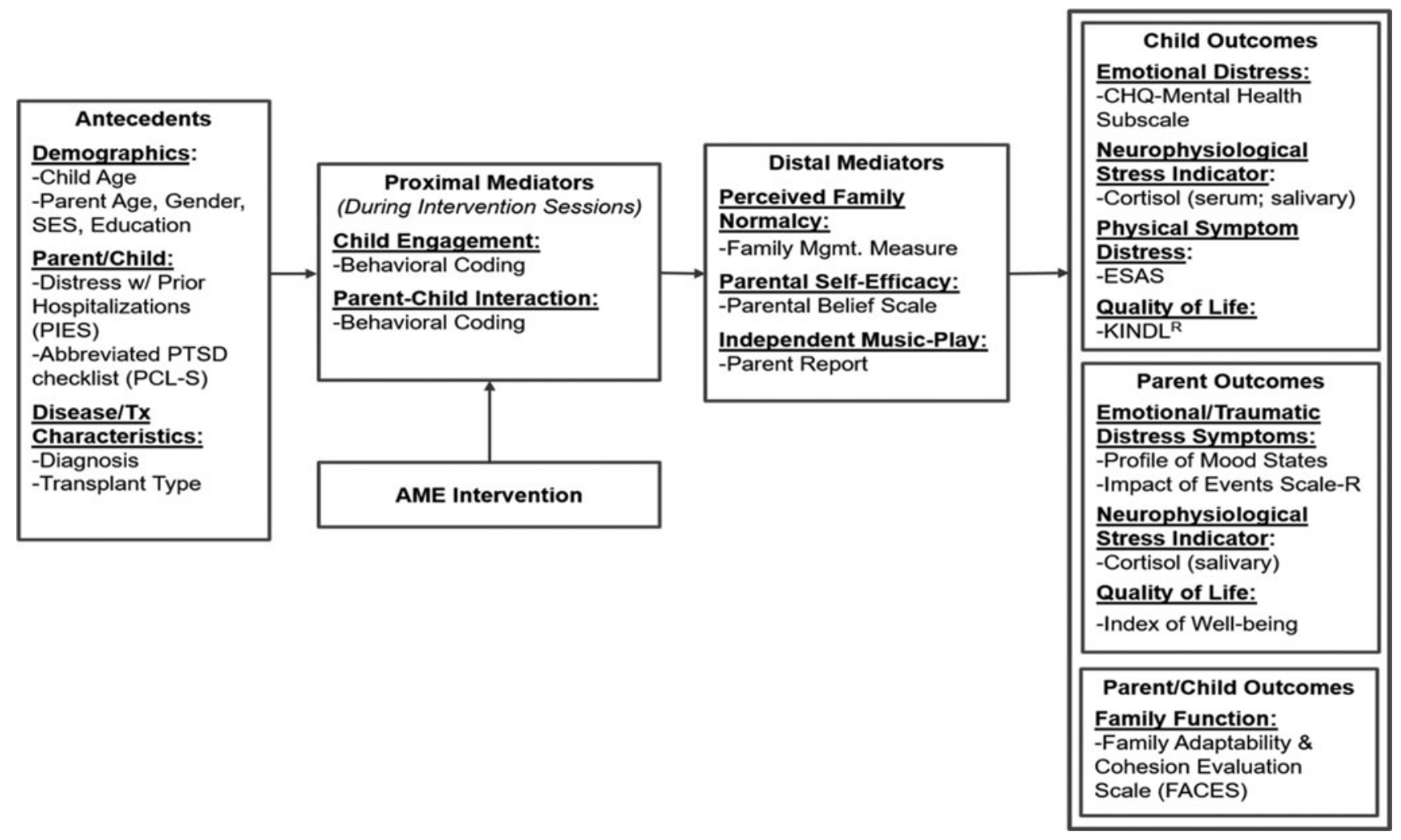

FIG. 1. Conceptual framework. AME, active music engagement; ESAS, Edmonton Symptom Assessment System; PCL-S, PTSD checklist; PIES, Prior Illness Experiences Scale.

The AME is designed to directly target potential proximal mediators of child engagement and caregiver-child interaction, ${ }^{19,21}$ as well as distal mediators of perceived family normalcy, ${ }^{39}$ caregiver confidence (self-efficacy) about their ability to support their child during treatment, ${ }^{40}$ and independent music play between therapist-led sessions. Outcomes include child outcomes (emotional distress, physical symptom distress, cortisol, and quality of life), caregiver outcomes (emotional distress, traumatic stress symptoms, cortisol, and quality of life), and family function.

\section{Study design and rationale}

In this one-group pilot study (Fig. 2), approved by the Indiana University Institutional Review Board, children and their caregivers will receive two 45-min AME sessions each week during the acute phase of HSCT until time of discharge (i.e., two sessions/week for duration of treatment). Session frequency and duration were selected based on preliminary studies and HSCT symptom trajectory. ${ }^{19-21,41}$ The total number of sessions will be based on the individual child's admission period to account for variations in treatment duration, to mimic standard care, and to avoid removal of AME as a supportive care service before discharge when children and caregivers still require support. The authors anticipate that a majority of patients will receive six sessions, over a 3-week period, and to collect data on the number of sessions each dyad receives to inform analysis and interpretation of findings.

Single-case designs were developed to facilitate examination of treatment when data can only be collected from a small number of individuals, such as when investigating different approaches to behavior modification among individuals with rare developmental disabilities. ${ }^{42}$ Using the single-case alternating treatment design, the authors compare levels of cortisol in blood and saliva samples collected from dyads on days when they receive AME sessions with levels of cortisol on days when they do not receive AME. Since relatively few children receive HSCT, the single-case design is ideal for evaluating interventions during transplants. ${ }^{43}$ The essential logic of the single-case design, as implemented in this study, is that levels of cortisol will be consistently and clearly lower on days when dyads receive AME than on days when they do not. If the analyses, as described below, reveal that this is the case, the authors may infer that AME caused observed reductions in cortisol. ${ }^{44}$

\section{Participants and recruitment}

Children/caregivers will be study eligible if the child (1) is 3-8 years of age (inclusive) at the time of enrollment; (2) will receive inpatient HSCT for a malignant or nonmalignant condition, including hemoglobinopathies; and (3) has one caregiver who agrees to be present for all sessions. Children/caregivers will not be eligible if (1) the caregiver or child does not speak English or (2) if the child has a significant cognitive impairment that may hinder their ability to participate, as determined by consultation with the attending HSCT physician, primary hematologist-oncologist, and caregivers. Eligibility will not be dependent on transplant type (autologous or allogeneic).

The authors will enroll children, ages 3-8 years, admitted for HSCT and one caregiver (i.e., parent or legal guardian) 


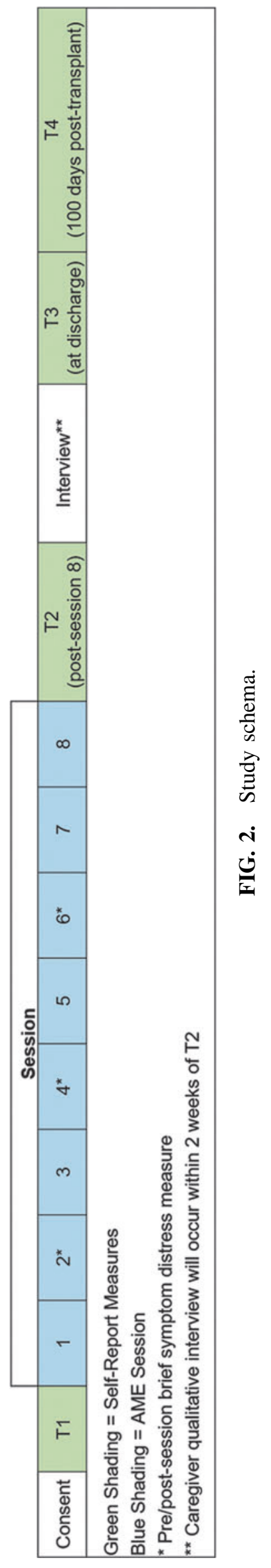

as dyads. The targeted sample size is four child-caregiver dyads, which will provide the information needed to determine the feasibility/acceptability of study procedures and refine intervention content. Certified research coordinators will use an eligibility checklist to identify potential participants, and a study team member will provide study information, verify eligibility, and obtain written caregiver consent/assent for children $\geq 7$ years.

\section{Active music engagement intervention}

Dyads will receive two 45-min AME sessions in private rooms at the HSCT unit each week for the duration of their inpatient stay. AME sessions were designed for delivery by a board-certified music therapist (MT-BC) who tailors musicbased play experiences to encourage active engagement in and independent use of music play as a strategy to manage distress. ${ }^{19-21}$ During sessions, the MT-BC provides dyads repeated opportunities to experience competence, autonomy, and meaningful interactions through music-based play activities and provides support/education about ways that children/caregivers can use music play to manage distress and sustain a sense of family normalcy while being hospitalized and following HSCT discharge. AME has three primary components: (1) therapist-led music-based play activities and sessions, (2) a music play resource kit (to promote independent music play), and (3) session planning and caregiver tip sheets that focus on ways to use music play during hospitalization and as dyads transition from hospital to home (Table 1).

\section{Biological sample collection}

The authors developed two sampling schedules based on transplant type (Figs. 3 and 4) to address differences in conditioning treatment protocols for autologous and allogeneic transplants and to avoid periods of treatment with corticosteroids, which can interfere with cortisol measurements. Biological samples collected will include blood (child) and saliva (child and caregiver). Blood (1 mL) will be collected from the child's central line as part of daily transplant laboratories (drawn 4-6 AM). The blood, in rapid serum tubes, will be sent immediately to the pathology laboratory for cortisol analysis using a Beckman Coulter UniCel DxI800 immunoassay system. Saliva will be collected from the child and caregiver by study staff at three different time points on each collection day: (1) up to $1 \mathrm{~h}$ before the AME session, (2) up to $1 \mathrm{~h}$ after the session, and (3) 1-3 h after the second collection. To collect saliva, the child and caregiver will be instructed to drool into $50-\mathrm{mL}$ conical tubes until $\sim 500 \mu \mathrm{L}$ of saliva is collected. The saliva will be immediately stored on dry ice and transferred to $-80^{\circ} \mathrm{C}$ until analysis. Salivary cortisol levels will be measured using an R\&D Systems cortisol parameter assay. For child participants, the authors will capture medical record data on any medications that can affect cortisol levels. In addition, caregivers will complete a questionnaire (for self and child) about activities or substances known to affect cortisol levels (e.g., sleep, exercise, and caregiver medications) and timings/details of food intake. ${ }^{45}$

For this single-case design, the authors will also collect biological measures on treatment and nontreatment days, controlling for time of day (to account for daily fluctuations 
Table 1. Active Music Engagement Intervention Components and Theoretical Principles

Intervention component Theoretical principles

Component 1: Music-Based Play Activities

Component 2: Music Play Resource Kit

Component 3: Session Planning and Caregiver Tip Sheets
(1) Predictable environment provides a structure that supports child competence.

Therapist uses familiar music activities to provide structure and increase child's ability to predict what will happen in their environment.

(2) Leveled activities help ensure success and support child competence.

Therapist tailors physical activity requirements to meet the individual needs of each child. Enables child success and engagement during periods of high or fluctuating symptom distress.

(3) Opportunities to make independent decisions support child autonomy.

Children choose from a variety of music play activities, and each activity includes a wide range of materials. Activities include a wide range of materials and activity options so that the child can make choices for self and others.

Therapist uses improvisational techniques to follow child-initiated changes in their music making (e.g., child changes tempo or style of playing).

(4) Activities structured to support caregiver-child interaction.

Activities structure and support reciprocal caregiver-child interactions. The therapist individualizes experiences to support increased frequency and quality of interactions.

Supports independent use of music play to manage distress between therapist-led sessions.

Activities mirror content from therapist-led sessions. The kit includes:

(1) Professional CD recording of music composed and/or arranged specifically for the AME intervention.

(2) Age-appropriate musical instrument and play materials that correspond to each activity.

(3) Activity cards designed to give children/caregivers at-a-glance information on ways they can use their kit.

(1) Promotes caregiver competence about how children use play to cope and ways to engage their child in music play during the transplant period.

(2) Promotes caregiver autonomy by empowering caregivers with skills/resources to support their child during treatment.

(3) Supports caregiver-child relationships through normalizing music-based play activities.

AME, active music engagement.

in cortisol) and potential order effects. As seen in Figure 3, the sampling schedule for autologous transplants includes eight collections (4 treatment days and 4 control days). The first four collections occur during conditioning for the transplant; and the remaining four occur poststem cell infusion. Note that the first collection serves as the baseline for autologous participants. Treatment and control days are linked (they occur 1 day apart and take place at the same time of day), with four linked collections scheduled over the course of the transplant.

The sampling schedule for allogeneic transplants (Fig. 4) is similar; however, the timing of collection is adjusted to account for drug interference that occurs during conditioning. Because allogeneic collections occur later in treatment, the authors will collect baseline blood samples during a routine clinic visit 1 week before admission. In addition, before side effects (e.g., mucositis) occur, the authors will schedule two practice collections to help children learn how to give saliva samples. In both transplant regimens, the number of collections exceeds the recommended number of three data points per condition established for single-case designs. $^{46}$

\section{Caregiver report measures}

Caregivers will complete self-report and caregiver proxy questionnaires at four time points (Table 2). Baseline mea- sures will be completed during a routine clinic visit, within 30 days of the child's scheduled HSCT admission. Time 2 measures will be completed post-AME session eight, Time 3 measures at the time of discharge (if discharge did not occur at time of session eight), and Time 4 measures at 100 days post-transplant during a subsequent clinic visit. In addition, caregivers will complete brief pre/postsession measures for caregiver distress/child symptom distress at sessions 2, 4, and 6. All measures will be administered by trained evaluators not involved with AME delivery, and all evaluation sessions audio-recorded for quality assurance monitoring. The authors selected questionnaires based on the study's theoretical framework (Fig. 1), with careful consideration of psychometric properties, sensitivity to change, and response burden. Table 2 provides a list of all measures, including psychometrics and administration schedule. ${ }^{4-53}$

\section{Caregiver qualitative interviews}

The authors will conduct semistructured qualitative interviews with caregivers to identify any changes that may be required for AME delivery during HSCT and evaluate acceptability of study activities/timelines related to biological sample collection, planned evaluations, and intervention delivery. Interviews will begin with an open-ended question to capture overall perceptions of the caregiver's experience (i.e., "Please tell me about your experience of participating in the 


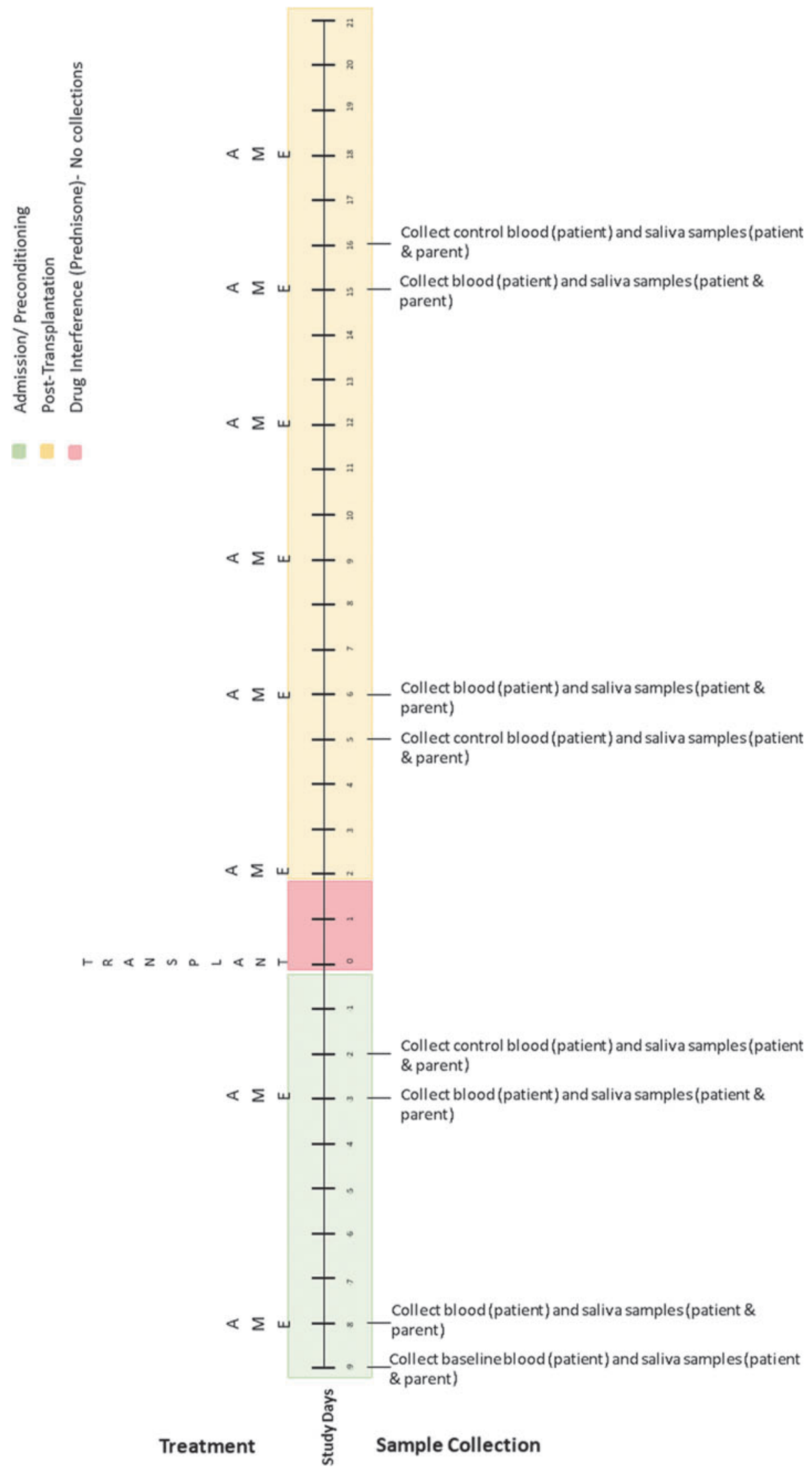

FIG. 3. Autologous transplant biological sample collection timetable. 


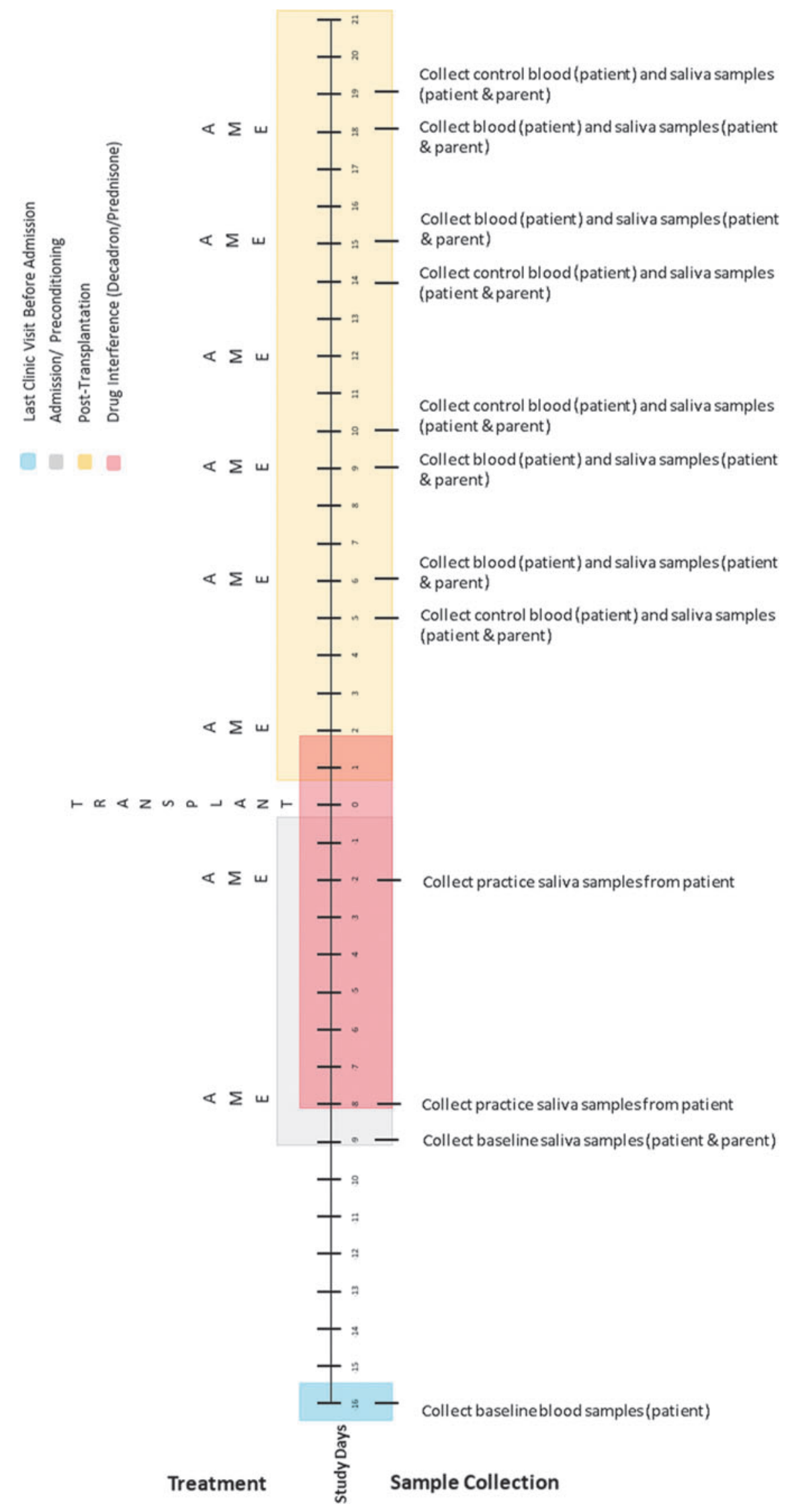

FIG. 4. Allogeneic transplant biological sample collection timetable. 
Table 2. Measures

\begin{tabular}{|c|c|c|c|c|c|}
\hline Variable(s) & Measure & $\begin{array}{l}\text { No. of } \\
\text { items }\end{array}$ & $\begin{array}{l}\text { Reliability } \\
\text { evidence }\end{array}$ & Admin. schedule & Completed by \\
\hline $\begin{array}{l}\text { Antecedent factors } \\
\text { Demographics } \\
\text { Parent/child age, parent } \\
\text { gender, SES, parent } \\
\text { education }\end{array}$ & Family Information Form & 3 & N/A & $\mathrm{T} 1$ & Parent \\
\hline $\begin{array}{l}\text { Prior distress } \\
\text { w/hospitalization }\end{array}$ & $\begin{array}{l}\text { Prior Illness Experiences } \\
\text { Scale }\end{array}$ & 13 & $0.78^{\mathrm{a}}$ & $\mathrm{T} 1$ & Parent \\
\hline Parent/child & $\begin{array}{l}\text { Abbreviated PTSD } \\
\text { Checklist (PCL-S) }\end{array}$ & 6 & $0.94^{\mathrm{a}}$ & $\mathrm{T} 1, \mathrm{~T} 2, \mathrm{~T} 3, \mathrm{~T} 4$ & Parent \\
\hline Disease characteristics & $\begin{array}{l}\text { Diagnosis and Treatment } \\
\text { Form }\end{array}$ & 2 & N/A & $\mathrm{T} 4$ & $\begin{array}{l}\text { Research } \\
\quad \text { Assistant (RA) }\end{array}$ \\
\hline $\begin{array}{l}\text { Treatment characteristics } \\
\text { Proximal mediators }\end{array}$ & Medication Data Form & N/A & N/A & $\mathrm{T} 1, \mathrm{~T} 2, \mathrm{~T} 3, \mathrm{~T} 4$ & RA \\
\hline $\begin{array}{l}\text { Child engagement } \\
\text { Parent-child interaction }\end{array}$ & $\begin{array}{l}\text { Behavioral Coding Form } \\
\text { Behavioral Coding Form }\end{array}$ & $\begin{array}{l}\text { N/A } \\
\text { N/A }\end{array}$ & $85^{0.85^{\mathrm{b}}}$ & $\begin{array}{l}\text { Sessions 2, 4, } 6 \\
\text { Sessions 2, 4, } 6\end{array}$ & $\begin{array}{l}\text { Trained Coder } \\
\text { Trained Coder }\end{array}$ \\
\hline $\begin{array}{l}\text { Distal mediators } \\
\text { Family normalcy } \\
\text { perspective }\end{array}$ & $\begin{array}{l}\text { Family Management } \\
\text { Measure } \\
\text { Family Life Difficulty } \\
\text { Subscale }\end{array}$ & 14 & $0.90^{\mathrm{a}}$ & $\mathrm{T} 1, \mathrm{~T} 2, \mathrm{~T} 3, \mathrm{~T} 4$ & Parent \\
\hline $\begin{array}{l}\text { Parent self-efficacy } \\
\text { Independent music play }\end{array}$ & $\begin{array}{l}\text { Parental Beliefs Scale } \\
\text { Parent Report }\end{array}$ & $\begin{array}{r}20 \\
2\end{array}$ & $\begin{array}{l}0.85^{\mathrm{a}} \\
\text { N/A }\end{array}$ & $\begin{array}{l}\text { T1, T2, T3, T4 } \\
\text { Sessions 2-6; T4 }\end{array}$ & $\begin{array}{l}\text { Parent } \\
\text { Parent }\end{array}$ \\
\hline $\begin{array}{l}\text { Child outcomes } \\
\text { Child emotional distress }\end{array}$ & $\begin{array}{l}\mathrm{CHQ}-\text { Mental Health } \\
\text { Subscale }\end{array}$ & 16 & $0.81^{\mathrm{a}}$ & $\mathrm{T} 1, \mathrm{~T} 2, \mathrm{~T} 3, \mathrm{~T} 4$ & Parent \\
\hline $\begin{array}{l}\text { Child physical symptom } \\
\text { distress } \\
\text { (mood, anxiety, pain, } \\
\text { fatigue, nausea) }\end{array}$ & $\begin{array}{l}\text { Edmonton Symptom } \\
\text { Assessment System }\end{array}$ & 5 & $0.69-0.80^{\mathrm{a}}$ & $\begin{array}{l}\mathrm{T} 1, \mathrm{~T} 4 \\
\quad \text { Sessions 2, 4, } 6\end{array}$ & Parent \\
\hline Child quality of life & $\mathrm{KINDL}^{\mathrm{R}}$ & 20 & $0.89^{\mathrm{a}}$ & $\mathrm{T} 1, \mathrm{~T} 2, \mathrm{~T} 3, \mathrm{~T} 4$ & Parent \\
\hline $\begin{array}{l}\text { Neurophysiological } \\
\text { indicator of stress }\end{array}$ & Cortisol (serum; salivary) & N/A & N/A & Appendix 5, 6 & $\begin{array}{l}\text { Nurse (serum); } \\
\text { RA (salivary) }\end{array}$ \\
\hline Parent outcomes & & & & & \\
\hline $\begin{array}{l}\text { Parent emotional and } \\
\text { traumatic stress }\end{array}$ & $\begin{array}{l}\text { Profile of Mood States-Short } \\
\text { Form }\end{array}$ & 37 & $0.99^{\mathrm{c}}$ & $\mathrm{T} 1, \mathrm{~T} 2, \mathrm{~T} 3, \mathrm{~T} 4$ & Parent \\
\hline symptoms & $\begin{array}{l}\text { Impact of Events Scale- } \\
\text { Revised (IES-R) }\end{array}$ & 22 & $0.84-0.91^{\mathrm{a}}$ & $\mathrm{T} 1, \mathrm{~T} 2, \mathrm{~T} 3, \mathrm{~T} 4$ & Parent \\
\hline $\begin{array}{l}\text { Parent distress (mood, } \\
\text { anxiety, fatigue) }\end{array}$ & $\begin{array}{l}\text { Edmonton Symptom } \\
\text { Assessment System }\end{array}$ & 3 & $0.69-0.80^{\mathrm{a}}$ & $\begin{array}{l}\mathrm{T} 1, \mathrm{~T} 4 \\
\quad \text { Sessions } 2,4,6\end{array}$ & Parent \\
\hline Parent quality of life & Index of Well-being & 9 & $0.93^{\mathrm{a}}$ & $\mathrm{T} 1, \mathrm{~T} 2, \mathrm{~T} 3, \mathrm{~T} 4$ & Parent \\
\hline $\begin{array}{l}\text { Neurophysiological } \\
\text { indicator of stress }\end{array}$ & Cortisol (salivary) & N/A & N/A & Appendix 6 & RA \\
\hline $\begin{array}{l}\text { Parent/child outcomes } \\
\text { Family function }\end{array}$ & FACES II & 30 & $0.90^{\mathrm{a}}$ & $\mathrm{T} 1, \mathrm{~T} 2, \mathrm{~T} 3, \mathrm{~T} 4$ & Parent \\
\hline $\begin{array}{l}\text { Qualitative interviews } \\
\text { Parent acceptability }\end{array}$ & Parent Interview & N/A & N/A & T4 & Parent \\
\hline
\end{tabular}

music play sessions with your child."'). Follow-up questions will include specific questions about the perceived benefit (or nonbenefit) of AME in managing stress, experiences with saliva collection, and the value of different intervention components (i.e., tip sheets, goal setting worksheet, and kit use). Interviews will occur within 2 weeks of Time 2 data collection (in the hospital or by phone). Trained personnel, not involved in AME delivery, will conduct audio-recorded interviews for subsequent transcription and analysis.

\section{Data analysis plan}

The following analysis includes a systematic plan to address primary and secondary aims of the proposed pilot 
study. Descriptive statistics will be computed for all variables to ensure data quality.

Research questions 1-3. Analyses will be descriptive. The authors will report the percentage of (1) eligible caregiver/child dyads who consent to study participation (feasibility threshold $=75 \%$ ) and reasons that eligible dyads decline study participation, (2) planned intervention activities that dyads complete (acceptability threshold $=75 \%$ ) and reasons for canceled, rescheduled, and missed sessions, and (3) planned measures that caregivers complete at Time 1, Time 2, Time 3, and Time 4 data collections (feasibility threshold $=75 \%$ ), including examination of missing data patterns.

Research question 4. Analyses will be descriptive. In the first portion of these analyses, the authors will report the percentage of cortisol samples collected from children (feasibility threshold $=75 \%$ ) and caregivers (feasibility threshold $=85 \%$ ). In the second portion, the authors will report the proportion of samples judged to be of sufficient quality for further analyses, such that cortisol values fall within the range for which the assay has been validated as well as the distribution of values collected from other children and caregivers across the study. Given the potential for children's samples to be altered by ingestion of food, drink, or medication, the authors will establish a lower feasibility threshold for children $(60 \%)$ than for their caregivers $(75 \%)$.

Research question 5. The authors will use a qualitative descriptive design with content analysis to analyze interview data. ${ }^{54}$ Procedures include (1) interviews transcribed and reviewed for accuracy; (2) category development through content analysis; and (3) findings validated by peer review to reach consensus.

\section{Biomarker analysis plan}

Assuming that the feasibility thresholds specified above are met, blood and salivary cortisol levels will be graphed to visualize trends. ${ }^{55}$ To complement the results of these visual analyses, the authors will compute Tau-U statistics. The Tau$\mathrm{U}$ statistic is a nonoverlap metric derived by comparing all unique pairs of data points (here, cortisol levels) between the treatment and control conditions. Before analysis, data will be inspected for linear trends indicative of serial conditioning effects. These effects may occur when cortisol levels measured at points in the intervention are subject to the current and prior effects of the intervention. If conditioning effects are detected, the calculation of the Tau-U statistic will be adjusted for linear trends using utilities embedded in the Tau$\mathrm{U}$ calculator. The Tau-U statistics will then be used to estimate an effect size for the treatment on levels of cortisol for each participant and for the sample as whole. ${ }^{56}$

\section{Discussion}

Importance

Pediatric HSCT has proven to be an effective treatment for many pediatric malignancies as well as certain nonmalignant hematologic conditions. Advances in condi- tioning regimens and donor options have also expanded to populations for whom HSCT can be beneficial, including metabolic disorders, immunodeficiencies, and even inflammatory bowel disease. ${ }^{57}$ While it is encouraging that HSCT is a therapeutic option for increasing numbers of otherwise incurable diseases, HSCT also raises concern that more children and caregivers will endure significant stress associated with the transplant and will need greater availability and variety of supportive care options. ${ }^{58} \mathrm{AME}$, as described in this protocol, not only provides support to the child and caregiver during the acute period of HSCT but also builds coping skills after HSCT when psychosocial concerns such as traumatic stress symptoms emerge. ${ }^{59,60}$ Because HSCT is a complex treatment, an important aspect of this study is to ensure that AME and study-related activities do not interfere with planned treatment protocols, thereby avoiding creation of undo stress for the treatment team and child-caregiver dyads. As such, this study represents an important step for refining AME for delivery during HSCT and advancing the understanding about the use of active music interventions to manage acute stress for this growing patient population.

\section{Method strength}

Conventional research designs (e.g., randomized control trials) require relatively large samples to assess treatment effects; however, as previously noted, single-case designs were developed for use in contexts where data can be collected from only a small number of individuals. Applying a single-case design to the study of HSCT will allow estimation of the effects of AME on an understudied population of children. Moreover, by collecting cortisol levels at multiple time points, it will be possible to isolate AME effects on different aspects of HPA axis activity (i.e., waking cortisol levels, baseline levels, or diurnal cortisol throughout the day) by comparing levels of cortisol that correspond to different aspects of HPA axis activity on treatment and control days. Additionally, hospitalization will provide a controlled environment where medical records can be used to identify events that may contribute to unexpected fluctuations in cortisol levels, allowing for more accurate data interpretation.

\section{Potential limitations}

For children with malignant disease requiring HSCT, there may be long-term effects of therapy on the HPA axis. ${ }^{29,61-63}$ This may create difficulties in interpretation of patient cortisol levels and the potential clinical benefit of AME. Collection of baseline cortisol may be useful in differentiating between long-term treatment effects and the effects of AME. Additionally, HSCT-related side effects, such as pain associated with mucositis or general malaise, might result in patients choosing not to provide a biological sample. Finally, the inability of consenting caregivers to be present for all AME sessions and saliva collections due to work or other caregiver responsibilities may result in missed collections.

This study will provide important information about the feasibility/acceptability of collecting cortisol samples at the frequency required for single-case design from young 
children and caregivers during a high-risk high-intensity treatment. In addition, findings will advance the understanding about the use of active music interventions to mitigate the inter-related distress experienced by children and caregivers during the transplant period.

\section{Author Disclosure Statement}

S.A.J. has received an honorarium for a speaking engagement from Novartis. For all other authors, no competing financial interests exist.

\section{Funding Information}

The authors would like to acknowledge the funding received from the Center for Enhancing Quality of Life (CEQL)-Indiana University School of Nursing, the IU Simon Cancer Center P30 Support Grant (P30CA082709), and the Class of 1964 Pilot Research Fund-Indiana School of Nursing. The authors would also like to acknowledge the Indiana University Melvin and Bren Simon Cancer Center Translational Research Core for assistance in developing the biological sample collection protocol.

\section{References}

1. Guilcher GMT, Truong TH, Saraf SL, et al. Curative therapies: Allogeneic hematopoietic cell transplantation from matched related donors using myeloablative, reduced intensity, and nonmyeloablative conditioning in sickle cell disease. Semin Hematol 2018;55:87-93.

2. Best M, Streisand R, Catania L, Kazak AE. Parental distress during pediatric leukemia and posttraumatic stress symptoms (PTSS) after treatment ends. J Pediatr Psychol 2001;26:299-307.

3. Kazak AE, Barakat LP, Meeske K, et al. Posttraumatic stress, family functioning, and social support in survivors of childhood leukemia and their mothers and fathers. J Consult Clin Psychol 1997;65:120-129.

4. Kazak AE, Baxt C. Families of infants and young children with cancer: A post-traumatic stress framework. Pediatr Blood Cancer 2007;49(7 Suppl):1109-1113.

5. Kazak AE, Boeving CA, Alderfer MA, et al. Posttraumatic stress symptoms during treatment in parents of children with cancer. J Clin Oncol 2005;23:7405-7410.

6. Santacroce S. Uncertainty, anxiety, and symptoms of posttraumatic stress in parents of children recently diagnosed with cancer. J Pediatr Oncol Nurs 2002;19:104111.

7. Graf A, Bergstraesser E, Landolt MA. Posttraumatic stress in infants and preschoolers with cancer. Psychooncology 2013;22:1543-1548.

8. Ingerski LM, Shaw K, Gray WN, Janicke DM. A pilot study comparing traumatic stress symptoms by child and parent report across pediatric chronic illness groups. J Dev Behav Pediatr 2010;31:713-719.

9. Virtue SM, Manne SL, Mee L, et al. Psychological distress and psychiatric diagnoses among primary caregivers of children undergoing hematopoietic stem cell transplant: An examination of prevalence, correlates, and racial/ethnic differences. Gen Hosp Psychiatry 2014;36:620-626.

10. Bruce M. A systematic and conceptual review of posttraumatic stress in childhood cancer survivors and their parents. Clin Psychol Rev 2006;26:233-256.
11. Kangas M, Henry JL, Bryant RA. Posttraumatic stress disorder following cancer. A conceptual and empirical review. Clin Psychol Rev 2002;22:499-524.

12. Kazak AE, Stuber ML, Barakat LP, et al. Predicting posttraumatic stress symptoms in mothers and fathers of survivors of childhood cancers. J Am Acad Child Adolesc Psychiatry 1998;37:823-831.

13. Stuber ML, Christakis DA, Houskamp B, Kazak AE. Posttrauma symptoms in childhood leukemia survivors and their parents. Psychosomatics 1996;37:254-261.

14. Stuber ML, Kazak AE, Meeske K, et al. Predictors of posttraumatic stress symptoms in childhood cancer survivors. Pediatrics 1997;100:958-964.

15. Hobbie WL, Stuber M, Meeske K, et al. Symptoms of posttraumatic stress in young adult survivors of childhood cancer. J Clin Oncol 2000;18:4060-4066.

16. Hatfield E, Cacioppo J, Rapson R. Emotional contagion. Curr Dir Psychol Sci 1993;2:96-99.

17. Robinson KE, Gerhardt CA, Vannatta K, Noll RB. Parent and family factors associated with child adjustment to pediatric cancer. J Pediatr Psychol 2007;32:400-410.

18. Robb SL, Hanson-Abromeit D. A review of supportive care interventions to manage distress in young children with cancer and parents. Cancer Nurs 2014;37:E1-E26.

19. Robb SL. The effect of therapeutic music interventions on the behavior of hospitalized children in isolation: Developing a contextual support model of music therapy. J Music Ther 2000;37:118-146.

20. Robb SL, Clair AA, Watanabe M, et al. A non-randomized [corrected] controlled trial of the active music engagement (AME) intervention on children with cancer. Psychooncology 2008;17:699-708.

21. Robb SL, Haase JE, Perkins SM, et al. Pilot randomized trial of active music engagement intervention parent delivery for young children with cancer. J Pediatr Psychol 2017;42:208-219.

22. Costanzo ES, Sood AK, Lutgendorf SK. Biobehavioral influences on cancer progression. Immunol Allergy Clin North Am 2011;31:109-132.

23. Padgett DA, Glaser R. How stress influences the immune response. Trends Immunol 2003;24:444-448.

24. Glaser R, Kiecolt-Glaser JK. Stress-induced immune dysfunction: Implications for health. Nat Rev Immunol 2005;5: 243-251.

25. Gunnar M, Quevedo K. The neurobiology of stress and development. Annu Rev Psychol 2007;58:145-173.

26. Post-White J, Fitzgerald M, Savik K, et al. Massage therapy for children with cancer. J Pediatr Oncol Nurs 2009;26:16-28.

27. Walco GA, Conte PM, Labay LE, et al. Procedural distress in children with cancer: Self-report, behavioral observations, and physiological parameters. Clin J Pain 2005;21: 484-490.

28. Lane D. The effect of a single music therapy session on hospitalized children as measured by salivary immunoglobulin A, speech pause time, and patient opinion likert scale [Electronic Thesis or Dissertation] 1991.

29. Rensen N, Gemke RJ, van Dalen EC, et al. Hypothalamicpituitary-adrenal (HPA) axis suppression after treatment with glucocorticoid therapy for childhood acute lymphoblastic leukaemia. Cochrane Database Syst Rev 2017;11: CD008727.

30. Moore IM. Advancing biobehavioral research in childhood cancer. J Pediatr Oncol Nurs 2004;21:128-131. 
31. Kang DH, Rice M, Park NJ, et al. Stress and inflammation: A biobehavioral approach for nursing research. West J Nurs Res 2010;32:730-760.

32. Robb S. Designing music therapy interventions for hospitalized children and adolescents using a contextual support model of music therapy. Music Ther Perspect 2003;21:27-40.

33. Robb, S. Coping and chronic Illness: Music therapy for children and adolescents with cancer. In: Robb S, ed. Music Therapy in Pediatric Healthcare Research and EvidenceBased Practice. Silver Spring, MD: American Music Therapy Association, 2003:101-135.

34. Stevens B, Croxford R, McKeever P, et al. Hospital and home chemotherapy for children with leukemia: A randomized cross-over study. Pediatr Blood Cancer 2006;47: 285-292.

35. Kazak AE, Cant MC, Jensen MM, et al. Identifying psychosocial risk indicative of subsequent resource use in families of newly diagnosed pediatric oncology patients. J Clin Oncol 2003;21:3220-3225.

36. Kazak AE, Barakat LP. Brief report: Parenting stress and quality of life during treatment for childhood leukemia predicts child and parent adjustment after treatment ends. J Pediatr Psychol 1997;22:749-758.

37. Barrera M, D'Agostino NM, Gibson J, et al. Predictors and mediators of psychological adjustment in mothers of children newly diagnosed with cancer. Psychooncology 2004; 13:630-641.

38. Langeveld NE, Grootenhuis MA, Voute PA, de Haan RJ. Posttraumatic stress symptoms in adult survivors of childhood cancer. Pediatr Blood Cancer 2004;42:604-610.

39. Knafl KA, Deatrick JA. Family Matters. The challenge of normalization for families of children with chronic conditions. Pediatr Nurs 2002;28:49.

40. Steele RG, Long A, Reddy KA, et al. Changes in maternal distress and child-rearing strategies across treatment for pediatric cancer. J Pediatr Psychol 2003;28:447-452.

41. Robb SL, Burns DS, Stegenga KA, et al. Randomized clinical trial of therapeutic music video intervention for resilience outcomes in adolescents/young adults undergoing hematopoietic stem cell transplant: A report from the Children's Oncology Group. Cancer 2014;120:909-917.

42. Barlow DH, Nock MK, Hersen M. Single-Case Experimental Designs: Strategies for Studying Behavior Change. London: Pearson, 2009.

43. Transplant Activity Report, Number of Transplants per Year. Online document at: https://bloodcell.transplant.hrsa .gov/research/transplant_data/transplant_activity_report/yearage_group.pdf accessed October 18, 2019.

44. Kazdin AE. Single-Case Research Designs: Methods for Clinical and Applied Settings. 2nd ed. New York: Oxford University Press, 2011.

45. Gibson EL, Checkley S, Papadopoulos A, et al. Increased salivary cortisol reliably induced by a protein-rich midday meal. Psychosom Med 1999;61:214-224.

46. Kratochwill TR, Hitchcock J, Horner RH, et al. Single-case intervention research design standards. Remedial Spec Educ 2013;34:26-38.

47. Knafl K, Deatrick JA, Gallo A, et al. Assessment of the psychometric properties of the Family Management Measure. J Pediatr Psychol 2011;36:494-505.

48. Melnyk BM, Feinstein NF, Moldenhouer Z, Small L. Coping in parents of children who are chronically ill: Strategies for assessment and intervention. Pediatr Nurs 2001;27:548-558.
49. Watanabe SM, Nekolaichuk CL, Beaumont C. The Edmonton Symptom Assessment System, a proposed tool for distress screening in cancer patients: Development and refinement. Psychooncology 2012;21:977-985.

50. Ravens-Sieberer U, Bullinger M. Assessing health-related quality of life in chronically ill children with the German KINDL: First psychometric and content analytical results. Qual Life Res 1998;7:399-407.

51. McNair D, Lorr M, Droppleman LF. POMS Manual for the Profile of Mood States. San Diego, CA: Educational and Industrial Testing Service, 1971.

52. Hyer K, Brown LM. The Impact of Event Scale-Revised: A quick measure of a patient's response to trauma. Am J Nurs 2008;108:60-68.

53. Olson DH, Gorall DM, Tiesel JW. FACES-IV Package: Administration. Roseville, MN: Life Innovations, Inc., 2006.

54. Vaismoradi M, Turunen H, Bondas T. Content analysis and thematic analysis: Implications for conducting a qualitative descriptive study. Nurs Health Sci 2013;15: 398-405.

55. Harrington M, Velicer WF. Comparing visual and statistical analysis in single-case studies using published studies. Multivariate Behav Res 2015;50:162-183.

56. Vannest KJ, Parker R, Gonen O, Adiguzel T. Single Case Research: web based calculators for SCR analysis. (Version 2.0) [Web-based application]. College Station, TX: Texas A\&M University, 2016. Online document at: singlecaseresearch.org, accessed February 5, 2020.

57. Salem GA, Selby GB. Stem cell transplant in inflammatory bowel disease: A promising modality of treatment for a complicated disease course. Stem Cell Investig 2017;4:95.

58. Boucher AA, Miller W, Shanley R, et al. Long-term outcomes after allogeneic hematopoietic stem cell transplantation for metachromatic leukodystrophy: The largest singleinstitution cohort report. Orphanet J Rare Dis 2015;10:94.

59. Lee SJ, Loberiza FR, Antin JH, et al. Routine screening for psychosocial distress following hematopoietic stem cell transplantation. Bone Marrow Transplant 2005;35:77-83.

60. Hierlmeier S, Eyrich M, Wolfl M, et al. Early and late complications following hematopoietic stem cell transplantation in pediatric patients-A retrospective analysis over 11 years. PLoS One 2018;13:e0204914.

61. Ahmad N, Abosoudah IF, Sobaihi MM, et al. Adrenal function following acute discontinuation of glucocorticoids in children with acute lymphocytic leukemia: A prospective study. Pediatr Hematol Oncol 2019;36:422-431.

62. Petersen KB, Muller J, Rasmussen M, Schmiegelow K. Impaired adrenal function after glucocorticoid therapy in children with acute lymphoblastic leukemia. Med Pediatr Oncol 2003;41:110-114.

63. Howell JC, Rose SR. Pituitary disease in pediatric brain tumor survivors. Expert Rev Endocrinol Metab 2019;14: 283-291.

Address correspondence to: Sheri L. Robb, PhD, MT-BC Indiana University School of Nursing 600 Barnhill Drive, NU E433 Indianapolis, IN 46202

USA

E-mail:shrobb@iu.edu 